\title{
AN ANALYSIS OF COMPETITIVENESS OF THE EU COUNTRIES USING THE DEPENDENT MIXTURE MODEL
}

As European Union countries are facing particularly difficult economic management decisions with challenging political and social ramifications, we try to find groups of countries which face a similar challenge of improving their competitiveness indicators. We focus on the dependent mixture model which additionally allows us to investigate the dynamic pattern of the competitiveness index and pillars organized into three sub-indices time series. This methodology will provide an opportunity to investigate which countries feature a similar level of competitiveness stability (are able to sustain their level of competitiveness) and which have similar regime-switching propensities. These results may contribute to the current policy discussion on measures for achieving the sustainable competitiveness of the European Union economies, EU strategy and reform programmes in separate member states.

Keywords: competitiveness, latent Markov models, dependent mixture model, EU countries

JEL Classifications: C15, E01, O11, O57

DOI: $10.15611 /$ aoe.2017.2.05

\section{INTRODUCTION}

In a globalizing economy, maintaining and enhancing external competitiveness has become of increasing concern to countries around the world. This applies in particular to EU candidate countries, whose small economies have to rely mainly on export-led growth. Improving competitiveness is also important in the context of the enhanced economic convergence required in order to join the Economic and Monetary Union (EMU) (Orszaghova et al, 2013, p.7).

In these years of the global economic slowdown, Europe's governments, businesses and consumers are looking ahead to future sources of economic growth. Beyond the immediate challenges of the European debt crisis and questions over the future of the Eurozone and the whole European Union, it is very important to revitalize economic growth and countries' competitiveness.

\footnotetext{
* Department of Statistics, University of Economics in Katowice.
} 
It should be emphasized that the EU as a whole could be competitive if the separate member states sought to eliminate or reduce barriers which may inhibit their competitiveness. First, the reform should embrace those countries where the level of competitiveness is the lowest because their impact weakens the position of the whole group.

This article looks in detail at the evaluation of competitiveness indicators over the past few years in the European Union countries. However the aim of this paper is not only to find groups of countries with similar competitiveness characteristics (featuring not only similar competitiveness indices in the last year), but also to investigate the dynamic pattern of the competitiveness indices during the last few years using the latent class models. The results of such analysis have a cognitional value for scientists, but they may be also interesting in the view of some challenges, such as formulating strategies of competitiveness.

The paper is organized as follows: after a short introduction, Section 1 provides a concise overview of a different competitiveness definitions and their measures. This is followed by the methodology we applied in the empirical part of the article, i.e. the dependent mixture model, its history and main assumptions. The majority of the paper (Section 4) involves a detailed analysis of competitiveness sub-factors for EU countries. The study focuses on finding different competitiveness regimes for the EU countries and providing the probabilities of switching between one regime and another. Our analysis is completed by the main findings and conclusion.

\section{DEFINING COMPETITIVENESS}

Competitiveness can be defined as the ability to face competition and to be successful when facing competition. Competitiveness would then be the ability to sell products that meet demand requirements (price, quality, quantity) and, at the same time, ensure profits over time that enable the firm to thrive. Competition may be within domestic markets (in which case firms, or sectors, in the same country are compared with each other) or international (in this case, comparisons are made between countries). Competitiveness can be then defined and measured at different levels of economic analysis: nations (macro level), sectors of economic activity at national and regional level (meso level) and firms (micro level). Research in the field has a variety of perspectives. There are studies involving macroeconomic, microeconomic, business, geographical and sectoral factors, which are always interrelated. Therefore researchers use the concept 
of competitiveness in many different ways (Buzzigoli and Viviani, 2006), often overlapping, using different measures, indicators and analytical methodologies.

There is, however, more or less a consensus on which measures could be used to assess competitiveness. Measurement can be made according to two disciplines. The first one focuses on trade success and measures competitiveness with the real exchange rate, comparative advantage indices, and export or import indices. The second one, the strategic management school, places emphasis on the firm's structure and strategy. In the latter, competitiveness is defined as cost leadership and non-price supremacy, with cost competitiveness measured according to various cost indicators as well as productivity and efficiency. More often non-price competitiveness indicators are used to measure the external competitiveness of a country. Thus we focus on this complex approach to competitiveness.

Competitiveness is therefore a relative measure. It is, however, a broad concept and there is no agreement on how to define it nor how to measure it precisely. Moreover, several authors stress that competitiveness does not have a definition in economic theory (e.g. Sharples, 1990; Ahearn et al., 1990). Although there is no agreed approach on how to define and measure competitiveness, we present one of the most popular definitions.

International competitiveness has long been considered vital to growth in industrial economies. With globalization, it is also becoming crucial for the developing countries that have long insulated themselves from world markets (Lall, 2001). One of the main reasons for the growing importance of international competitiveness is technological. The rapid pace of innovation and the resulting promise of productivity increase makes it more costly to insulate economies from international trade and investment. Since new technologies benefit all activities, traded and non traded, quick access to such technologies in the form of new products, equipment and knowledge becomes vital for the welfare of the nation.

The relation of these factors is causing significant changes to the location of productive activity across countries, and so to new patterns of global trade and national comparative advantage. There is a continuing surge of activities and functions seeking more efficient locations across the globe, led mainly by multinational corporations but also in some cases by other agents such as buyers and retailers (Dicken, 1998).

Competitiveness of a country is also defined as "the ability of a country to produce goods and services that meet the test of the international markets and simultaneously to maintain and expand the real income and also raise 
the welfare level of its citizens" (Haque, 1995). However the concept of competition power should not be totally explained only by the ability of a country's productivity, it should also be explained by the firm's level of competition power and the industrial level competition skills.

A broader approach to competitiveness which is defined as "the extent to which a country is able to compete in global markets" is presented by the European Central Bank (Orszaghova et al, 2013, p. 11).

The Organization for Economic Cooperation and Development (OECD) defines competitiveness as the "ability of companies, industries, regions, nations, and supranational regions to generate, while being and remaining exposed to international competition, relatively high factor income and factor employment levels on a sustainable basis" (Hatzichronologou, 1996). The European Commission uses the following definition: "a sustained rise in the standards of living of a nation or region and as low a level of involuntary unemployment as possible" (European Commission, 2009).

For more than three decades the World Economic Forum's annual Global Competitiveness Reports have studied and benchmarked the many factors underpinning national competitiveness. From the outset, the goal has been to provide insight and stimulate discussion among all stakeholders on the best strategies and policies to help countries to overcome the obstacles to improving competitiveness. In the current challenging economic environment, this work is a critical reminder of the importance of structural economic fundamentals for sustained growth.

The World Economic Forum (WEF) defines competitiveness as the set of institutions, policies and factors that determine the level of productivity of a country. The level of productivity, in turn, sets the level of prosperity that can be earned by an economy. The productivity level also determines the rates of return obtained by investments in an economy, which in their turn are the fundamental drivers of its growth rates. In other words, a more competitive economy is one that is likely to sustain growth. The concept of competitiveness thus involves static and dynamic components. Although the productivity of a country determines its ability to sustain a high level of income, it is also one of the central determinants of its returns to investment, which is one of the key factors explaining an economy's growth potential (WEF, Global Competitiveness Report 2012-2013, p. 4).

Although there are different theoretical approaches to the measurement of competitiveness, we focus in our empirical analysis on the well known indices presented by the Global Competitiveness Report (prepared by the World Economic Forum). The WEF's annually published Global Competitiveness 
Report carries out respective computations of the competitiveness index by different indicators. The Global Competitiveness Report focuses on economic welfare and increasing standards of living while making computations and rankings of the countries. According to the Global Competitiveness Report 2012-2013, Poland ranks 41st.

Hence the indicators used in this yearbook are firmly regarded as the factors which are crucial for achieving high growth levels. In the WEF's Global Competitiveness Report (GCR) 2012-2013, over 100 variables are used for 144 countries. These variables are grouped into 12 pillars, which are the sources of national competitiveness, each measuring different aspects of competitiveness: Institutions, Infrastructure, Macroeconomic Environment, Health and Primary Education, Higher Education and Training, Goods Market Efficiency, Labour Market Efficiency, Financial Market Development, Technological Readiness, Market Size, Business Sophistication and Innovation.

The GCI attributes higher relative weights to those pillars that are more relevant for an economy given its particular stage of development. That is, although all the 12 pillars matter to a certain extent for all countries, the relative importance of each one depends on its particular stage of development. To implement this concept, the pillars are organized into three sub-indices, each critical to a particular stage of development.

Table 1

Stages of 12 pillars of competitiveness according to Global Competitiveness Yearbook 2012-2013

\begin{tabular}{|c|c|c|}
\hline \multicolumn{3}{|c|}{ GLOBAL COMPETITIVENESS INDEX } \\
\hline $\begin{array}{l}\text { Basic requirements } \\
\text { sub-index }\end{array}$ & $\begin{array}{c}\text { Efficiency enhancers } \\
\text { sub-index }\end{array}$ & $\begin{array}{c}\text { Innovation } \\
\text { and sophistication factors } \\
\text { sub-index }\end{array}$ \\
\hline $\begin{array}{l}\text { Pillar 1. Institutions } \\
\text { Pillar 2. Infrastructure } \\
\text { Pillar 3. Macroeconomic } \\
\text { environment } \\
\text { Pillar 4. Health and } \\
\text { primary education }\end{array}$ & $\begin{array}{l}\text { Pillar 5. Higher education and } \\
\text { training } \\
\text { Pillar 6. Goods market efficiency } \\
\text { Pillar 7. Labour market efficiency } \\
\text { Pillar 8. Financial market } \\
\text { development } \\
\text { Pillar 9. Technological readiness } \\
\text { Pillar 10. Market size }\end{array}$ & $\begin{array}{l}\text { Pillar 11. Business } \\
\text { sophistication } \\
\text { Pillar 12. Innovation }\end{array}$ \\
\hline $\begin{array}{l}\text { Key for factor-driven } \\
\text { economies (in stage 1) }\end{array}$ & $\begin{array}{l}\text { Key for efficiency-driven } \\
\text { economies (in stage 2) }\end{array}$ & $\begin{array}{l}\text { Key for innovation-driven } \\
\text { economies (in stage } 3 \text { ) }\end{array}$ \\
\hline
\end{tabular}

Source: WEF, Global Competitiveness Report 2012-2013, p. 8. 
The basic requirements sub-index groups the pillars most critical for countries in the factor-driven stage. The efficiency enhancers sub-index includes those pillars critical for countries in the efficiency-driven stage, and the innovation and sophistication factors sub-index includes the pillars critical to countries in the innovation-driven stage (see WEF, Global Competitiveness Report 2012-2013, p. 9). The three sub-indices are shown in Table 1.

Twenty-one of the EU countries are in stage 3, i.e. innovation-driven economies. The Baltic States, i.e. Estonia, Latvia, Lithuania and two of the Central Europe countries - Poland and Hungary - are in transition from stage 2 to stage 3. Only Bulgaria belongs to efficiency-driven economies.

\section{LATENT AND HIDDEN MARKOV MODELS}

In latent class analysis (Lazersfeld, 1950a, b; Lazersfeld and Henry, 1968) it is assumed that each observation comes from one of a number of classes (groups) and models each with its own probability distribution. When longitudinal data are to be analyzed, the research questions concern some form of change over time. When change is discussed in relation to latent class models, we are referring to a change that is in some sense categorical or discrete, such as transition between latent classes, rather than a continuous change in level. When latent class analysis (LCA) is applied three or more times, this approach is called repeated-measures LCA (RMLCA). The other approach, latent transition analysis (LTA), is a variation of the latent class model that is designed to model not only the prevalence of latent class membership, but the incidence of transitions over time in latent class membership. The RMLCA approach works best when a small number of indicators of the latent variable are measured three or more times. Then a latent class model can be fitted so that the latent classes correspond to different patterns of categorical or discrete change over time (Collins and Lanza, 2011, p. 182).

Latent transition models are known as latent Markov models and are frequently used in the social sciences, in different areas and application. In psychology they are used for modelling learning processes (Wickens, 1982; Schmittmann et al, 2006). In economics, latent Markov models are so-called regime switching models (see e.g. Kim, 1994 and Ghysels, 1994). Other applications include speech recognition (Rabiner, 1989) and genetics analysis (Krogh, 1998). In these areas of application, latent Markov models are usually referred to hidden Markov models. A more gentle introduction 
into hidden Markov models with application is the book by Zucchini and MacDonald (2009). An overview of hidden Markov models with extensions can be found in Frühwirth-Schnatter (2006), as well as in Cappe, Moulines and Ryden (2005).

Hidden Markov models are formally equivalent to latent Markov models. However in practice the literature on each of these models are largely separated. HMMs originate from engineering applications such as speech recognition (Rabiner, 1989), whereas latent Markov models originate in sociology and political science (Langeheine, Van de Pol, 1990). HMMs are typically applied to long univariate time series such as speech streams or stock market prices. In contrast, latent Markov models were considered as extensions of latent class models (McCutcheon, 1987) with repeated measurements. In latent class models the goal is to classify persons into a finite number of distinct types. The latent Markov model then is applicable whenever questionnaires are administered repeatedly and the goal is to study changes, e.g. in political preferences of large groups of people. In latent Markov models the focus is on short multivariate time series with many cases, whereas HMMs are mostly applied to long (univariate) time series of a single process or individual.

The term "dependent mixture model" was originally proposed by Leroux, Puterman (1992) and used by Visser and Speekenbrink (2010) to relate both to the latent and hidden Markov model.

\section{DEPENDENT MIXTURE MODEL}

The main assumption of a dependent mixture model is that at any time point the observations are distributed as a mixture of $u$ components (or states), and that time-dependencies between the observations are due to timedependencies between the mixture components (i.e. probabilities of transitions between the components). These dependencies are assumed to follow a first-order Markov chain. Moreover, the observation at a particular time point is independent of observations at other time points conditionally on the latent state. The latter implies that the observed competitiveness indices (analyzed in the empirical part of the analysis) in time $t$ depends only on the latent state at time $t$ and is often referred to as the local independence assumption.

The general form of our data is $\mathbf{X}_{1: T}=\left(X_{1}^{1}, \ldots, X_{1}^{m}, X_{2}^{1}, \ldots, X_{2}^{m}, X_{T}^{1}, \ldots, X_{T}^{m}\right)$, for an $m$-variate time series of length $T$. We use $\mathbf{X}_{t}$ as shorthand for 
$X_{t}^{1}, \ldots, X_{t}^{m}$. The joint likelihood of observations given model parameters $\Theta$ can be written as (Visser, Speekenbrink, 2010):

$$
P=\left(\mathbf{X}_{t}, S_{t} \mid \boldsymbol{\Theta}\right)=\pi_{s} \mathbf{b}_{S_{t}}\left(\mathbf{X}_{1}\right) \prod_{t=1}^{T-1} a_{s r} \mathbf{b}_{S_{t}}\left(\mathbf{X}_{t+1}\right),
$$

where the following elements are:

$S_{t}-$ is an element of $S=[1, \ldots, u]$, a set of $u$ latent classes, states or regimes,

$\pi_{s}=P\left(S_{1}=s\right)-$ an initial-state probability, i.e. the probability of having a particular latent initial class/state at time $t=1$,

$a_{s r}=P\left(S_{t+1}=r \mid S_{t}=s\right)-$ a transition of state $s$ to state $r$.

Assuming a homogenous transition process with respect to time, we achieve the latent transition matrix $\mathbf{A}$ of transition probabilities $a_{s r}$, with $s, r, \ldots, u$ denoting the probability of switching from latent state $s$ to latent state $r$.

$$
\mathbf{A}=\left[\begin{array}{ccc}
a_{11} & \cdots & a_{1 u} \\
\vdots & \ddots & \vdots \\
a_{u 1} & \cdots & a_{u u}
\end{array}\right]
$$

The row sums of transition matrix equal to one.

$\mathbf{b}_{S_{t}}$ - is a vector of observation densities $b_{r}^{j}=P\left(X_{t}^{j} \mid S_{t}=r\right)$ that provides conditional densities of observations $X_{t}^{j}$ associated with latent class/state $r$, $j=1, \ldots, m$. The example data $b_{r}^{j}$ could be a Gaussian or Bernoulli distribution.

Maximum likelihood (ML) estimation of the parameters of dependent mixture model can be solved by means of the Expectation-Maximization (EM) algorithm (Dempster et al, 1977). The E step computes the joint conditional distribution of the $t+1$ latent variables given the data and the current estimates of the model parameters. In the M step, standard complete data ML methods are used to update the unknown model parameters using the expanded data matrix with the estimated densities of the latent variables as weights.

An important modelling issue is the choice of $s$, the number of clusters needed to capture the unobserved heterogeneity across observations. The 
selection of the proper number of clusters is typically based on information criterion such as the Bayesian Information Criterion (BIC) (Schwarz, 1978) or the Akaike Information Criterion (AIC) (Akaike, 1974).

\section{COMPETITIVENESS OF THE EU COUNTRIES - THE EMPIRICAL STUDY}

Our analysis deals with the cross-sectional dataset with twenty seven EU countries measured over seven years (2006-2007, 2007-2008, 2008-2009, 2009-2010, 2010-2011, 2011-2012, 2012-2013) ${ }^{1}$, for a total of 189 observations. The public data set is available at the World Economic Forum website. All the computations and graphics in this paper have been done in depmixS4 (Visser and Speekenbrink, 2013) package of R.

The following variables (sub-indices) were used in the analysis:

- Global Competitiveness Index - GCI,

- Basic requirements,

- Efficiency enhancers,

- Innovation and sophistication.

A reasonable theoretical approach might indicate that there are $\operatorname{two}^{2}$ or three latent groups of countries - more competitive, less competitive or those countries who are in the middle (in the case of three classes) ${ }^{3}$. We can test this hypothesis using a dependent mixture model. The optimal number of clusters was chosen using information criteria (BIC, AIC). We decided to compare the results for two and three latent classes because the difference in information criterion between two and three clusters was very small. Moreover during the period 2006-2012, the countries experienced shocks and big crises, therefore we considered both two and three latent states. We estimated the parameters of two and three components using the EM algorithm.

Each latent state can be characterized by the mean return $(\hat{\mu})$ and standard deviation $(\hat{\sigma})$ of the country's sub-indices. The standard deviations

\footnotetext{
${ }^{1}$ Since 2006-2007 the World Economic Forum has been publishing the Global Competitiveness Index on the basis of the same sub-indices.

${ }^{2}$ The groups of new and old EU member states.

${ }^{3}$ In line with the economic theory of stages of development, the GCI assumes that economies are in the factor-driven (the first stage), the efficiency-driven (the second stage) and the innovation-driven (the third stage) stages of development (see Table 1 and the Global Competitiveness Report 2012-2013, pp. 8-9).
} 
provide information about volatility (i.e. the risk) of each latent state: a low volatility state can be interpreted as a more "stable" competitiveness regime.

In Table 2 the latent states and its characteristics are presented. The first column in Table 2 provides the size of each latent state which indicates the proportion of time observations classified into a particular state, and thus represents their level of occurrence in the period that is analyzed. For example, $60 \%$ of time points are allocated into state one which represents the modal state, while state two contains only $40 \%$ of the observations.

Table 2

Estimated priors, means and standard deviations for the dependent mixture model with two components

\begin{tabular}{l|l|c|c|c|c|c|c|c|c}
\hline \multirow{2}{*}{ Index } & \multirow{2}{*}{ Size } & \multicolumn{2}{|c|}{ GCI } & \multicolumn{2}{c|}{$\begin{array}{c}\text { Basic } \\
\text { requirements }\end{array}$} & \multicolumn{2}{c|}{$\begin{array}{c}\text { Efficiency } \\
\text { enhancers }\end{array}$} & \multicolumn{2}{c}{$\begin{array}{c}\text { Innovation and } \\
\text { sophistication }\end{array}$} \\
\cline { 3 - 10 } & & $\hat{\mu}$ & $\hat{\sigma}$ & $\hat{\mu}$ & $\hat{\sigma}$ & $\hat{\mu}$ & $\hat{\sigma}$ & $\hat{\mu}$ & $\hat{\sigma}$ \\
\hline State & & 4.37 & 0.21 & 4.81 & 0.35 & 4.38 & 0.21 & 3.85 & 0.34 \\
\hline State 1 & 0.60 & 5.31 & 0.21 & 5.76 & 0.23 & 5.19 & 0.20 & 5.21 & 0.33 \\
\hline State 2 & 0.40 & 5 &
\end{tabular}

Source: own study.

The analysis of mean returns and standard deviations allows insight about the main features of the different phases which characterize the dynamics of the countries' competitiveness. State 1 for example identifies low competitiveness periods since they are characterized by the low value of $\hat{\mu}$ and the high value of $\hat{\sigma}$. According to their size this state occurs more often. On the other hand, state 2 with a higher value of $\hat{\mu}$ refers to high competitiveness periods. This state represent the phase of stability of the countries economic situation (lower value of $\hat{\sigma}$ ). Furthermore it can be noted (from Table 2) that within each latent state $\hat{\mu}$ and $\hat{\sigma}$ differ among the country sub-indices. In particular the basic requirements indices have higher values (by $44 \%$ higher in the first state and $45 \%$ higher in the second state) with respect to the general competitiveness index. Moreover, the value of $\hat{\sigma}$ for the basic requirement index in the first latent state has the highest value.

On the other side efficiency enhancers as well as the innovation and sophistication factors sub-indices usually have lower values with respect to the general competitiveness index ${ }^{4}$. The only exception is represented by the

\footnotetext{
${ }^{4}$ The efficiency enhancers sub-indices are by $1 \%$ higher in the first state and by $12 \%$ lower in the second state, innovation and sophistication factors sub-indices are by $52 \%$ lower in the first state and by $10 \%$ lower in the second state with respect to the general competitiveness index.
} 
first latent state which is characterized by a $1 \%$ higher value of efficiency enhancers sub-index than the general competitiveness indicator. The results reported in Table 2 provide an innovative measurement of risk and expected return and allow us to identify alternative investment strategies in different countries.

Bulgaria, Cyprus, the Czech Republic, Estonia (with the exception of the first year of the analysis), Greece, Hungary, Italy, Latvia, Lithuania, Malta, Poland, Portugal, Romania, the Slovak Republic, Slovenia and Spain are in the first state. The second state comprises: Austria, Belgium, Denmark, Finland, France, Germany, Ireland, Luxembourg, Netherlands, Sweden and the UK, with the non-stable position of Ireland which was in the first state in years 2009-2010, 2010-2011, 2011-2012, and in the second state during four years of the analysis ${ }^{5}$. Therefore we can say that the first class consists of the countries that joined the EU after 1 May 2004 (excluding Italy, Spain and Portugal), and the second class consists of the old EU member states.

A further relevant set of information provided by the dependent mixture model is represented by the latent transition matrix $\mathbf{A}$ which shows the probability of switching from one latent state to another. The results related to the dynamics of the country competitiveness indices are reported in Table 3 . The values on the main diagonal of transition matrix represent the state's persistence, that is the probabilities of remaining in a particular phase (state). For example, the probability of staying in latent state 1 is $a_{11}=0.67$ while it is not so unlikely to remain in state $2\left(a_{22}=0.44\right)^{6}$. The off-diagonal entries $a_{s r}$ indicate the probabilities of country regime switching: for instance, when the economy of the country is experiencing a crisis, the competitiveness indicators are not well represented by latent state 1 at time $t+1$, and this unattractive, uncompetitive phase might be persistent, because transition to a stronger competitive countries position is quite unlikely $\left(a_{12}=0.33\right)$. It is also interesting to notice that when we are in the positive market regime at time $t$,

\footnotetext{
${ }^{5}$ The time period of the analysis could have an influence on the position of Ireland which was very high in the ranking at the beginning of our analysis. The non-stable position for this country in the years of the analysis could be explained by the substantial instability of the economy, which was an evident problem in 2009. Thus the country joined the team of PIIGS nations.

${ }^{6}$ The probabilities on the main diagonal of the transition matrix cannot be considered as stable but there are also far from the minimum level of 0.05 . It should be emphasized that the transition probabilities from state 2 to state 1 is more likely than remaining in state 2 , which means that maintaining competitiveness at this stage of development is much more difficult than switching to the less competitive state 1 .
} 
it may persist also at time $t+1$ with probability $a_{22}=0.44$, but it may also shift to the worse competitive period phase represented by state 1 with a higher probability ( $\left.a_{21}=0.56\right)$.

We can exploit the information provided by the switching probabilities reported in Table 3 in order to evaluate the reliability of the prediction capability of the dependent mixture model. Table 3 shows that some regime switching can be predicted quite accurately because their transition probabilities are high, for instance the probability of remaining in latent state one is relatively easy to predict. There are no transition probabilities close to 0.05 which could complicate prediction (this could make competitive regime at time $t+1$ quite difficult to predict precisely).

Table 3

Latent transition matrix for two states

\begin{tabular}{l|c|c}
\hline \multicolumn{1}{c|}{ State $\boldsymbol{s}$ / State $\boldsymbol{r}$} & State 1 & State 2 \\
\hline State 1 & 0.67 & 0.33 \\
\hline State 2 & 0.56 & 0.44 \\
\hline
\end{tabular}

Source: own study.

As mentioned before, we also estimated the parameters for three latent states which are presented in Table 4.

Table 4

Estimated prior, mean and standard deviation for the dependent mixture model with three components

\begin{tabular}{l|c|c|c|c|c|c|c|c|c}
\hline \multirow{2}{*}{ Index } & \multirow{2}{*}{ Size } & \multicolumn{2}{|c|}{ GCI } & \multicolumn{2}{c|}{$\begin{array}{c}\text { Basic } \\
\text { requirements }\end{array}$} & \multicolumn{2}{c|}{$\begin{array}{c}\text { Efficiency } \\
\text { enhancers }\end{array}$} & \multicolumn{2}{c}{$\begin{array}{c}\text { Innovation and } \\
\text { sophistication }\end{array}$} \\
\cline { 3 - 10 } & & $\hat{\mu}$ & $\hat{\sigma}$ & $\hat{\mu}$ & $\hat{\sigma}$ & $\hat{\mu}$ & $\hat{\sigma}$ & $\hat{\mu}$ & $\hat{\sigma}$ \\
\hline State & & 5.31 & 0.21 & 5.75 & 0.24 & 5.18 & 0.20 & 5.21 & 0.33 \\
\hline State 1 & 0.40 & 5.31 & 0.14 & 4.95 & 0.27 & 4.47 & 0.15 & 3.99 & 0.24 \\
\hline State 2 & 0.44 & 4.47 & 0.14 & 0.20 & 4.13 & 0.15 & 3.42 & 0.16 \\
\hline State 3 & 0.16 & 4.19 & 0.11 & 4.40 & 0.20 &
\end{tabular}

Source: own study.

Table 4 provides information on the three states that were identified, that is the average proportion of countries in state $s$ over time and the mean and variance of the competitiveness sub-indices in the three latent states. The probability of being in state 1,2 and 3 is $0.40,0.44$ and 0.16 , respectively. 
State 1 identifies the best performing competitiveness periods since they are characterized by the highest value of $\hat{\mu}$. On the other hand, state 2 with a lower value of $\hat{\mu}$ refers to the less competitive periods. According to the size this state occurs more often. State 3 contains only $16 \%$ of observations and represents the least competitive periods for EU countries. It can be noted that this state is characterized by the lowest values of $\hat{\mu}$, and includes countries with lower volatility. Furthermore, it can be emphasized that the basic requirements indices have higher values with respect to the general competitiveness index. Moreover the value of $\hat{\sigma}$ for the innovation and sophistication factors sub-index in the first latent state has the highest value (0.33).

The efficiency enhancers and the innovation and sophistication factors sub-indices usually have lower values with respect to the general competitiveness index. The only exception is represented by the second latent state which is characterized by the same value of efficiency enhancers sub-index like the general competitiveness index.

Table 5

Latent transition matrix for three states

\begin{tabular}{l|c|c|c}
\hline State $\boldsymbol{s}$ / State $\boldsymbol{r}$ & State 1 & State 2 & State 3 \\
\hline State 1 & 0.44 & 0.34 & 0.22 \\
\hline State 2 & 0.45 & 0.42 & 0.13 \\
\hline State 3 & 0.00 & 0.92 & 0.08 \\
\hline
\end{tabular}

Source: own study.

The transition probability matrix given in Table 5 shows that countries which were in the first latent status had a probability of 0.44 remaining there over time. If they did transition, they were most likely to transition to the second latent state (0.34). Those countries in the second latent state had a 0.42 probability of remaining there, their most likely transition was back to the first state (0.45). Countries of the third state had the lowest probability of remaining stable over time. They were most likely to transition to the second latent state (0.92) and had a negligible (rounded to 0.0 ) probability of transition to the most competitive state.

In the first class there are the best performing countries: Austria, Belgium, Denmark, Finland, France, Germany, Ireland, Luxemburg, Netherlands, Sweden, and the UK. Estonia was in this class in 2006-2007. The second class comprises less competitive countries: Cyprus, the Czech 
Republic, Estonia, Hungary, Italy, Latvia, Lithuania, Malta, Poland, Portugal, Slovenia, and Spain. It is worth noting that only in the first year of the analysis Greece was in this state, and Estonia was not. Latvia also changed position in four periods of time: 2008-2009, 2009-2010, 20102011, 2011-2012, and was back in this class in the last year of the analysis. The non-stable position in the second class refers also to Ireland (20092010, 2010-2011, 2011-2012) and Poland, that was in the less competitive class 3 during the first three years. The Slovak Republic was also in this class during five years; its position worsened during the last two years.

The third state indicates the least competitive economies. Countries always belonging to this class are Bulgaria, Greece and Romania, with the exception of Greece in 2006-2007 (belonging then to the second class). Poland was also in the third class during the first three years, and Latvia in 2009-2012. This class also included the Slovak Republic in the last two years of the analysis (previously belonging to the first class).

We can say that the first class includes northern EU-member countries (with the exception of France and Ireland). The second state comprises the southern and east-central EU-member countries. "Ireland, Spain, Portugal and Greece are treated as countries of the 'European Periphery' and as recipients, for a period of more than ten years, of various financing arrangements aimed at supporting and strengthening their competitiveness" (Garelli, 2006).

The last state comprises Bulgaria, which belongs to efficiency-driven economies, and two countries (Poland and Latvia) which were considered by the WEF as countries in transition (between stages 2 and 3). There is also Greece experiencing huge economic problems, and Slovakia, one of the youngest members of the Eurozone.

The two clusters could not be the only one choice (according to information criterion) but lead to a consistent representation of the competitiveness variable dynamics, clearly defining two distinct types of regime switching which is coherent with many facts in economics. Moreover, it is close to the traditional distinction made between the 15 original members and the 12 countries that joined after 2004 .

The dependent mixture model defines the different competitiveness regimes for the EU countries and provides the probabilities of switching between one regime and another. First, this approach provides a methodologically correct solution able to differentiate the latent evaluation with respect to the country competitiveness phases. The latent transition probabilities enable to predict the market regime at time $t+1$ quite accurately by referring to the highest diagonal values in transition matrix. 


\section{CONCLUSIONS}

The EU as a union remains diversified in terms of the level of competitiveness of its member states (and prospects of improvement) in different years. Most often the competitiveness of countries is compared on the basis of the previous year's indices. We found and characterized groups of EU countries with a similar ability to sustain a high level of competitiveness during the last few years. We also answered the question of which countries are prone to switch their competitiveness position. We found two groups of countries using the extended latent class model for short multivariate time series. One group, with the weaker competitive position as well as the higher state persistence and lower probability of transition to another group, comprises: Bulgaria, Cyprus, the Czech Republic, Estonia, Greece, Hungary, Italy, Latvia, Lithuania, Malta, Poland, Portugal, Romania, the Slovak Republic, Slovenia and Spain. The other group comprises countries with a higher level of competitiveness, but in a less stable position: Austria, Belgium, Denmark, Finland, France, Germany, Ireland, Luxemburg, Netherlands, Sweden and the UK.

The simultaneous analysis of the time series allows a better comparison of country dynamics compared to the application of cluster analysis for each year separately. The knowledge of the latent state characteristics and the transition probabilities are decisive in order to properly measure the latent competitiveness stability of all of the EU countries. Furthermore, the classification of every time point of the time series in homogenous nonobservable states offers a contribution to model-based clustering for financial time series and panel data (Frühwirth-Schnatter and Kaufmann, 2008; Otranto, 2008; Costa and De Angelis, 2012) which is receiving growing attention in the statistical literature.

This article discusses which countries can be more successful in terms of economic performance and which countries should catch up with the group of leaders in competitiveness to have a positive impact on the EU as a whole. The results and the detailed analysis of the estimated parameters as well as the transition matrix of the model may also contribute to the current policy discussion on measures for achieving sustainable competitiveness of the European Union economies, strategy and reform programmes in the separate member states. 


\section{REFERENCES}

Ahearn, M., Culver, D., Schoney, R., Usefulness and Limitations of COP Estimates for Evaluating International Competitiveness: A Comparison of Canadian and U.S. Wheat, American, "Journal of Agricultural Economics", Vol. 72, No. 5, pp. 1283-1291, 1990.

Akaike, H., A New Look at Statistical Model Identification, "IEEE Transactions on Automatic Control", Vol. 19, pp. 716-723, 1974.

Buzzigoli, L., Viviani A., Firm and System Competitiveness: Problems of Definition, Measurement and Analysis, [in:] Viviani, A., Firms and System Competitiveness. Firenze University Press, Italy, 2009.

Cappe, O., Moulines, E., Ryden, T., Inference in Hidden Markov Models. Springer-Verlag, New York, 2005.

Collins, L. M., Lanza, S. T., Latent Class and Latent Transition Analysis with Applications in the Social, Behavioral, and Health Sciences. John Wiley and Sons, 2011.

Costa, M., De Angelis, L., A Dynamic Analysis of Stock Markets through Multivariate Latent Markov Models [in:] Ingrassia, S., Rocci, R., Vichi, M., New Perspectives in Statistical Modeling and Data Analysis, Studies in Classification, Data Analysis, and Knowledge Organization, pp. 311-318. Springer-Verlag, 2011.

Dempster, A. P., Laird, N. P., Rubin, D. B., Maximum Likelihood for Incomplete Data via the EM Algorithm (with discussion), "Journal of the Royal Statistical Society", Vol. 39, pp. 1-38, 1977.

Dicken, P., Global Shift: Transforming the World Economy. Paul Chapman, London, 1998.

European Commission, European Competitiveness Report 2008, European Commission, 2009.

Frühwirth-Schnatter, S., Finite Mixture and Markov Switching Model, Springer-Verlag, New York, 2006.

Frühwirth-Schnatter, S., Kaufmann, S., Model-Based Clustering of Multiple Time Series, "Journal of Business \& Economic Statistics, American Statistical Association”, Vol. 26, pp. 78-89, 2008.

Garelli, S., Competitiveness of Nations: The Fundamentals, IMD World Competitiveness Yearbook, 2006.

Ghysels, E., On the Periodic Structure of the Business Cycle, "Journal of Business and Economic Statistics", Vol. 12 (3), pp. 289-298, 1994.

Hatzichronoglou, T., Globalisation and Competitiveness: Relevant Indicators, "OECD Science, Technology and Industry Working Papers", Paris OECD Publishing, Organisation for Economic Co-operation and Development, 1996.

Haque, I., Technology and Competitiveness, [in:] Haque, I., Trade, Technology and International Competitiveness. The World Bank, Washington, D. C., 1995.

Kim, C. J., Dynamic Linear Models with Markov-switching, "Journal of Econometrics", Vol. 60, pp. 1-22, 1994.

Krogh, A., An Introduction to Hidden Markov Models for Biological Sequences [in:] Salzberg, L. S., Searls, B. D., Kasif, S. (eds.), Computational Methods in Molecular Biology, pp. 45-63. Elsevier, Amsterdam, 1998.

Lall, S., Competitiveness, Technology and Skills. Edward Elgar, Cheltenham, 2001. 
Langenheine, R., Van de Pol, F., Fitting Higher Order Markov Chains, "Methods of Psychological Research Online", Vol. 5, pp. 32-55, 2001.

Lazarsfeld, P. F., The Logical and Mathematical Foundations of Latent Structure Analysis, [in:] Stouffer, A. S., Measurement and Prediction, the American Soldier: Studies in Social Psychology in World War II, pp. 362-412. Princeton University Press, Princeton,1950a.

Lazarsfeld, P. F., The Interpretation and Computation of Some Latent Structures, [in:] Stouffer, A. S., Measurement and Prediction, the American Soldier: Studies in Social Psychology in World War II, pp. 413-472, Princeton University Press, Princeton, $1950 \mathrm{~b}$.

Lazarsfeld, P. F., Henry, N. W., Latent Structure Analysis. Houghton Mifflin, Boston, 1968.

Leroux, B. G., Puterman, M. L., Maximum-Penalized-Likelihood Estimation for Independent and Markov-Dependent Mixture Models, "Biometrics", Vol. 48, 1992.

McCutcheon, A. L., Latent class analysis, Beverly Hills, Sage University Paper series on Quantitative Applications in the Social Sciences, series No. 07-064, 1987.

Orszaghova, L., Savelin, L., Schudel, W., External Competitiveness of EU Candidate Countries, Occasional Paper Series, No 141, available at http://www.ecb.europa.eu, accessed in January 2013.

Otranto, E., Clustering Heteroskedastic Time Series by Model-based Procedures, "Computational Statistics \& Data Analysis", Vol. 52, pp. 4685-4698, 2008.

Rabiner, L. R., A tutorial on Hidden Markov Models and Selected Applications in Speech Recognition, Proceedings of IEEE, Vol. 77, No 2, pp. 267-295, 1989.

Schmittmann, V. D., Visser, I., Raijmakers, M. E. J., Multiple Learning Modes in the Development of Rule-based Category-learning Task Performance, "Neuropsychologia", Vol. 44, No 11, pp. 2079-2091, 2006.

Schwarz, G., Estimating the Dimension of a Model, "Annals of Statistics", Vol. 6, pp. 461$-464,1978$.

Sharples, J., Cost of Production and Productivity in Analyzing Trade and Competitiveness, “American Journal of Agricultural Economics", Vol. 72, No. 5, pp. 1278-1282, 1990.

Visser, I., Speekenbrink, M., Package 'depmixS4', available at https://cran.r-project.org/ web/packages/ depmixS4/depmixS4.pdf.

Visser, I., Speekenbrink, M. (2010), depmixS4: An R Package for Hidden Markov Models, "Journal of Statistical Software", Vol. 36, No 7, pp. 1-21, available at http://www. jstatsoft.org/v36/i07/.

Wickens, T. D., Models for Behavior: Stochastic Processes in Psychology. W. H. Freeman and Company, San Francisco,1982.

World Economic Forum (2012), "Global Competitiveness Report 2012-2013", available at http://www3.weforum.org/docs/WEF_GlobalCompetitivenessReport_2012-13.pdf.

Zucchini, W., MacDonald, I., Hidden Markov Models for Time Series: An Introduction Using $R$. Monographs on Statistics and Applied Probability, Boca Raton, CRC Press, 2009.

Received: September 2014, revised: September 2016 